\title{
Synthesis and screening for biological potential of some substituted chalcones
}

\author{
K. R. Gupta ${ }^{1, *}$, S. Badole ${ }^{2}$, J. K. Gupta ${ }^{3}$, S. V. Singh ${ }^{4}$ \\ ${ }^{1}$ Professor, ${ }^{2-4}$ Student, Department of Pharmaceutical Chemistry, Smt. Kishoritai Bhoyar College of Pharmacy, Nagpur, \\ Maharashtra, India
}

*Corresponding Author:

Email: krg1903@gmail.com

\begin{abstract}
The present paper describes the synthesis and antibacterial as well as antioxidant activity of new chalcone derivatives derived from p-chloroacetopheneone. In the present work the reaction of p-chloroacetophenone with different substituted aromatic aldehyde. The newly synthesized chalcones (A-D) were analysed by their spectral data TLC, IR, UV and melting point. These newly synthesized compounds were evaluated for in-vitro antioxidant activity by Diphenyl Picryl Hydrazine (DPPH) model using ascorbic acid as standard and for antimicrobial activity by Cup Plate method on gram positive and gram negative bacterial strain using amoxicillin as standard.
\end{abstract}

Keywords: Chalcone, Antimicrobial, Antioxidant, P-chloroacetophenone, Aromatic aldehyde.

\section{Introduction}

Chalcones are well known intermediates for synthesizing various heterocyclic compounds and flavones. Chalcone is an aromatic ketone that forms the central core for many biological compounds. Chalcones are chemically 1, 3-diphenyl-2-propene-1-one which consists of two aromatic rings that are linked by an aliphatic three carbon $\alpha, \beta$-unsaturated carbonyl system. Chalcones possess a completely delocalized $\pi$ electron system on both the phenyl ring and a conjugated double bond. There is relatively low redox potential for the molecules that possess such system and also they have the greater probability of undergoing electron transfer reactionChalcones are also known as benzalacetophenone or beta-phenyl-alpha-benzoylethylene. ${ }^{1,2}$

The compounds with the backbone of chalcones have been reported to possess various biological activities such as antimicrobial, anti-inflammatory, analgesic, antiplatelet, antiulcerative, antimalarial, anticancer, antiviral, antileishmanial, antioxidant, antitubercular, antihyperglycemic, immunomodulatory, inhibition of chemical mediators release, inhibition of leukotriene B, inhibition of tyrosinase and inhibition of aldose reductase activities. Some chalcones possess bactericidal, antifungal and insecticidal activity and some of their derivatives are reported to be antimutagenic. The presence of a reactive $\alpha, \beta$ -

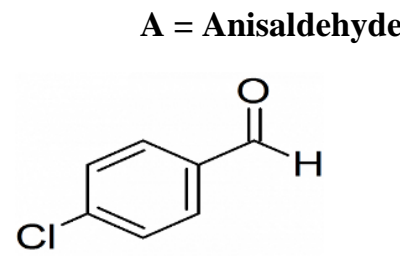

unsaturated keto function in chalcones is found to be responsible for their antimicrobial activity. ${ }^{3-5}$

Chalcones having an $\alpha, \beta$ unsaturated carbonyl group are versatile synthons for various chemical transformations. The chemistry of chalcones has taken an important place in organic chemistry; the research in this area is encouraged because of development of bacterial resistance to widely used antibiotics of this type.

\section{Materials and Method \\ General procedure for the synthesis of chalcones derivatives by Claisen-Schmidt condensation ${ }^{1,6-7}$}

Equimolar quantities $(12 \mathrm{~g}, \quad 0.1 \mathrm{~mol})$ of $\mathrm{P}$ chloroacetophenone and respective aldehydes $(10.6 \mathrm{~g}$, $0.7 \mathrm{~mol}$ ) were mixed and dissolved in minimum amount $(15 \mathrm{ml})$ of alcohol. To this, aqueous potassium hydroxide solution $(0.003 \mathrm{~mol})$ was added slowly and mixed occasionally for $1.5 \mathrm{~h}$, at room temperature. After completion of the reaction, the reaction mixture was kept for 14-16 $\mathrm{h}$ at room temperature. The potassium salt of chalcone was separated by ice-cold $\mathrm{HCl}(10 \%, 30 \mathrm{ml})$. The separated solid was filtered and washed with ice cold water till the washing was neutral to litmus. It was purified by recrystallization using ethanol and dried at room temperature.

Various Substituted Benzaldehyde:<smiles>COc1ccc(C=O)cc1</smiles> 


$$
\text { C = Cinnamaldehyde }
$$<smiles>O=C/C=C/c1ccccc1</smiles>

\section{Characterization of Synthesized compounds}

Melting point determination: The melting point was determined by filling the sample in the capillary, keeping it in the appropriate position in the melting point apparatus and the temperature at which the sample starts meting/got completely melted was noted.

TLC: The solutions of the compounds were prepared in methanol. The solvent system employed was pet ether: ethyl acetate (2:3). The solution of the compound was spotted on TLC plate using glass capillaries and after development spots were visualized in the UV chamber at $254 \mathrm{~nm}$.

UV Spectrum: The UV absorption spectrum of the synthesized compound was recorded using V-630 Jasco UV spectrophotometer by dissolving synthesized chalcone derivatives in methanol and the solution was scanned in the wavelength range $200-400 \mathrm{~nm}$ against blank.

IR spectral study: The IR spectra were recorded using the $\mathrm{KBr}$ pellet method in the range of $400-4000 \mathrm{~cm}^{-1}$

\section{Evaluation of biological potential Antioxidant Activity ${ }^{8}$}

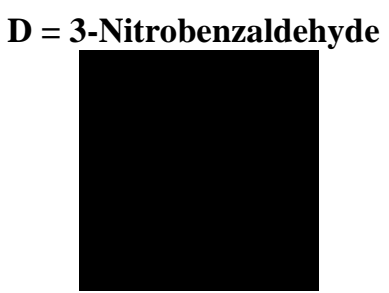

In vitro antioxidant model 1, 1-diphenyl-2picrylhydrazyl radical (DPPH) scavenging activity was used (as it is a model for lipophilic radicals that initiate lipid peroxidation.) Solvent used in the test was methanol.

\section{DPPH free-radical scavenging activity}

In-vitro antioxidant activity of newly synthesized compounds was performed by DPPH model. It based on determining the free radical inhibitory ability of different antioxidant by using very stable free radical such as 2, 2diphenyl-1-picrylhydrazyl (DPPH) in methanol. Stock solution of DPPH in methanol was prepared. Stock solution of DPPH $100 \mu \mathrm{L}$ was added to $3.0 \mathrm{~mL}$ of methanol and absorbance was recorded at $516 \mathrm{~nm}$. The various concentrations of synthesized compounds (12.5, 25,50 and $100 \mu \mathrm{g} / \mathrm{mL}$ ) were also prepared. All sample solutions $1.0 \mathrm{~mL}$ each was diluted with $3.0 \mathrm{~mL}$ with methanol and $100 \mu \mathrm{L}$ of stock solution of DPPH was added. Test tubes were kept for $30 \mathrm{~min}$ in light to complete the reaction. After $30 \mathrm{~min}$, absorbance of each test tube was recorded at $516 \mathrm{~nm}$ on UV-VIS spectrophotometer against methanol as a blank.

The DPPH free radical scavenging activity was calculated using the following formula:

$$
\% \text { scavenging }=\frac{\text { Absorbance of control }- \text { Absorbance of test sample }}{\text { Absorbance of control }}
$$

Where;

a. Control is absorbance of a DPPH solution without compound

b. Test is the absorbance of the test compound with DPPH.

The degree of discoloration indicates the free radical scavenging efficiency of the compound. Ascorbic acid was used as the free radical scavenger reference compound.

\section{Antimicrobial Activity ${ }^{9}$}

Cup Plate Method: It is one of the common methods for the evaluation of antimicrobial activity, includes preparation of bore on the sterilized agar plate and pouring the test compound and measurement of zone of inhibition.

\section{Microorganism}

The following microorganisms were used to study the antibacterial activity.

a. Bacillus subtilis - Gram positive bacteria

b. Staphylococcus aureous - Gram positive bacteria

c. Escherichia coli - Gram negative bacteria

d. Pseudomonas aeruginosa- Gram negative bacteria

Standard: Amoxicillin

Solvent: Dimethylsulfoxide

All the test compounds were tested at $25 \mu \mathrm{g}, 50 \mu \mathrm{g}, 75$ $\mu \mathrm{g}$ and $100 \mu \mathrm{g}$. 
Preparation of the medium: The medium was prepared by dissolving the specified quantity of the dehydrated medium in purified water by heating on a water bath and were dispensed in $100 \mathrm{ml}$ volume conical flasks. The conical flasks were closed with cotton plugs and were sterilized by autoclaving at $121^{\circ} \mathrm{C}(15 \mathrm{lb}$. psig) for 15 minutes.

The contents of the conical flasks were poured aseptically into sterile petridishes are allowed to solidify. These sterilized Medias were used to subculture the bacterial culture.

\section{Procedure}

Each petridish was filled to a depth of 6-8 $\mathrm{mm}$ with a nutrient agar medium that was previously inoculated with suitable inoculums of suitable test organism, and then allowed to solidify. The petridish were specially selected with flat bottom and were placed on level surface so as to ensure that the layer of medium is in uniform thickness. The petridishes were sterilized at $160-170{ }^{\circ} \mathrm{C}$ in hot air oven for $30 \mathrm{mins}$ before use. Small sterile borer of uniform size was placed approximately at $10 \mathrm{~cm}$ height, having an internal diameter of approximately 6-8 $\mathrm{mm}$ and made of aluminium (or) stainless steel. Each plate was divided in to four equal portions along the diameter. To each portion one cylindrical cavity was made in medium with the help of sterile borer. These four cavities are for test compounds and two plates are for the standard. The petridishes were incubated at $37^{\circ} \mathrm{C}$ for 18 hours. Diameter of the zone of inhibition was measured and the average diameter for each sample was calculated. The diameter obtained by the test sample was compared with that produced by standard amoxicillin.

\section{Result and Discussion}

This study presents the synthesis and screening of antimicrobial and antioxidant activities of four chalcones (A-D). The syntheses of above chalcones were accomplished using p-chloroacetophenone with different aromatic benzaldehyde derivatives.

The alkaline condensation of $\mathrm{p}$-chloroacetophenone with p-methoxybenzaldehyde, p-chlorobenzaldehyde, m-nitro benzaldehyde and cinnamaldehyde gives the corresponding chalcones. All the chalcones were purified by recrystallisation from ethanol. Chalcones A, $\mathrm{B}$ and $\mathrm{C}$ are yellow colored crystalline compound and the chalcone $\mathrm{D}$ is a brown colored powder. The purity of test compound was checked by melting point determination. The results are shown in Table 1 Further the UV spectra of all the synthesized compounds were taken in methanol as a solvent. The spectra reveals that almost all the chalcones shows UV absorption in the range of 300-350 $\mathrm{nm}$. Generally it is known that the chalcones absorb light in UV region and transmit in the remaining region. The graph reveals that almost all synthesized chalcone derivatives show absorption in the UV range 300$350 \mathrm{~nm}$. This absorption is to be assigned to $\mathrm{n}-\pi$ transition and may be attributed to the excitation in the aromatic ring and carbonyl group. The data noted for peaks in UV spectra are recorded in Table 2 . The Rf value calculated for the synthesized compounds are recorded in the Table 3

The structure of synthesized compounds was established by IR spectral data. All the compounds gave satisfactory IR data (Fig. No. 5,6,7,8 with respect to compound A-D) correlation with the assigned structures are as follows:

\section{Compound A}

The IR peak at $1656 \mathrm{~cm}^{-1}$ suggesting the presence of $\mathrm{C}=\mathrm{O}(\mathrm{a}, \beta$ - unsaturated ketone group). The peak at 2841 $\mathrm{cm}^{-1}, \quad 2972 \mathrm{~cm}^{-1}, \quad 3005 \mathrm{~cm}^{-1}, \quad 3035 \mathrm{~cm}^{-1}, \quad 3068 \mathrm{~cm}^{-}$ ${ }^{1}$ indicates that the presence of $=\mathrm{C}-\mathrm{H}$ (aliphatic and aromatic) stretching. The IR peak at $800 \mathrm{~cm}^{-1}$ indicates the presence of $\mathrm{C}-\mathrm{Cl}$ stretching.

\section{Compound B}

The IR peak at $1656 \mathrm{~cm}^{-1}$ suggesting the presence of $\mathrm{C}=\mathrm{O}$ (Str) group. The IR peak at $2848 \mathrm{~cm}^{-1}, 2916 \mathrm{~cm}^{-1}$, $3001 \mathrm{~cm}^{-1}, 3028 \mathrm{~cm}^{-1}, 3071 \mathrm{~cm}^{-}$indicates the presence of aliphatic and aromatic $\mathrm{C}-\mathrm{H}$ stretching. The IR peak at $742 \mathrm{~cm}^{-1}$ indicates the presence of aromatic bending. The IR peak at $800 \mathrm{~cm}^{-1}$ indicates the presence of $\mathrm{C}-\mathrm{Cl}$ streching.

\section{Compound C}

The IR peak at $1668 \mathrm{~cm}^{-1}$ suggesting the presence of $\mathrm{C}=\mathrm{O}$ (Str) group The IR peak at $2864 \mathrm{~cm}^{-1}, 2972 \mathrm{~cm}^{-1}$, $3010 \mathrm{~cm}^{-1}, 3039 \mathrm{~cm}^{-1}, 3064 \mathrm{~cm}^{-1}$ suggesting the presence of aromatic and aliphatic C-H stretch. The IR peak at $1668 \mathrm{~cm}^{-1}$ indicates the presence of $\mathrm{C}=\mathrm{C}$ alkene stretching. The IR peak at $723 \mathrm{~cm}^{-1}$ indicates the presence of aromatic bending. The IR peak at $800 \mathrm{~cm}^{-}$ ${ }^{1}$ indicates the presence of $\mathrm{C}-\mathrm{Cl}$ stretching.

\section{Compound D}

The IR peak at $1668 \mathrm{~cm}^{-1}$ suggesting the presence of $\mathrm{C}=\mathrm{O}(\mathrm{Str})$ group. The IR peak at $2864 \mathrm{~cm}^{-1}, 2972 \mathrm{~cm}^{-1}$, $3010 \mathrm{~cm}^{-1}, 3039 \mathrm{~cm}^{-1}, 3064 \mathrm{~cm}^{-1}$ suggesting the presence of aromatic and aliphatic C-H stretch. The peak at 1398 $\mathrm{cm}^{-1}$ indicates presence of $\mathrm{NO}_{2}$ stretching group.

DPPH (1, 1-diphenyl-2-picrylhydrazyl) radical scavenging activity was measured for all the chalcones (A-D) (Table 4). Ascorbic acid, the well-known antioxidant was used in the test for comparing the results, compound A appears to be the best among all the tested compounds. It was found that the chalcone $\mathbf{A}$ posseses more antioxidant activity as compare to ascorbic acid. Chalcone $\mathbf{C}$ was found to be more free radical scavenger in the concentration of $12.5 \mathrm{ug} / \mathrm{ml}$.

Statistical significance for antioxidant activity of synthesized compound was evaluated. Fig 1 shows that compound $\mathrm{C}$ exhibit significant anti-oxidant activity on the minimal concentration i.e. $12.5 \mathrm{ug} / \mathrm{ml}$ as compared with standard drug ascorbic acid whereas compound A 
and D Shows inhibition on $25 \mathrm{ug} / \mathrm{ml}$, compound D on $50 \mathrm{ug} / \mathrm{ml}$ and $\mathrm{A}, \mathrm{C}$ and $\mathrm{D}$ on $100 \mathrm{ug} / \mathrm{ml}$ when compared at same dose of ascorbic acid

The four synthesized chalcones were screened for their antimicrobial activity (Table 5a and 5b). They were tested against four bacterial species namely S.aureus, B. subtilis (gram positive bacteria) and E.coli, P.aeruginosa (gram negative bacteria). The technique used was agar cup plate method using amoxicillin as standard.

It was found that all the four chalcones possess less antimicrobial activity as compare to standard towards the gram positive bacteria (B.subtilis). Only the chalcone A showed the zone of inhibition in S.aureus at a concentration of $100 \mathrm{ug} / \mathrm{ml}$.

Antimicrobial activity against P.aeruginosa was found to be more satisfactory in all the four compounds. The antimicrobial activity against E. coli was found more in all the four compounds at a concentration of $75 \mathrm{ug} / \mathrm{ml}$. So we can say that the synthesized chalcones are more active against the gram negative bacteria and thus can be used for treating infections caused by gram negative bacteria.
Table 1: Observations of Melting point

\begin{tabular}{|c|c|}
\hline Compounds & Melting Point $\left({ }^{\circ} \mathbf{C}\right)$ \\
\hline A & $110-114$ \\
\hline B & $120-124$ \\
\hline C & $126-130$ \\
\hline D & $140-144$ \\
\hline
\end{tabular}

Table 2: UV analysis of synthesized compounds

\begin{tabular}{|c|c|c|}
\hline Compound & Peaks In (Nm) & Absorbance \\
\hline $\mathrm{A}$ & 245 & 0.571 \\
& 343 & 1.174 \\
\hline $\mathrm{B}$ & 244 & 0.457 \\
& 315 & 0.994 \\
\hline $\mathrm{C}$ & 260 & 0.588 \\
& 340 & 1.117 \\
\hline $\mathrm{D}$ & 237 & 0.399 \\
& 267 & 0.617 \\
\hline
\end{tabular}

Table 3: Observation of TLC analysis

\begin{tabular}{|c|c|}
\hline Compound & $\mathbf{R}_{\mathbf{f}}$ \\
\hline $\mathrm{A}$ & 0.82 \\
\hline $\mathrm{B}$ & 0.84 \\
\hline $\mathrm{C}$ & 0.81 \\
\hline $\mathrm{D}$ & 0.78 \\
\hline P-chloroacetophenone & 0.64 \\
\hline
\end{tabular}

Table 4: Antioxidant Activity: Percentage Inhibition of Free Radicals Using DPPH Method

\begin{tabular}{|c|c|c|c|c|c|c|c|c|}
\hline \multirow[t]{2}{*}{ Compound } & \multicolumn{2}{|c|}{$12.5 \mu \mathrm{g} / \mathrm{ml}$} & \multicolumn{2}{|c|}{$25 \mu \mathrm{g} / \mathrm{ml}$} & \multicolumn{2}{|c|}{$50 \mu \mathrm{g} / \mathrm{ml}$} & \multicolumn{2}{|c|}{$100 \mu \mathrm{g} / \mathrm{ml}$} \\
\hline & $\begin{array}{c}\text { Absorb- } \\
\text { ance }\end{array}$ & $\begin{array}{c}\% \\
\text { Inhibition }\end{array}$ & $\begin{array}{c}\text { Absorb- } \\
\text { ance }\end{array}$ & $\begin{array}{c}\% \\
\text { Inhibition }\end{array}$ & $\begin{array}{c}\text { Absorb- } \\
\text { ance }\end{array}$ & $\begin{array}{c}\% \\
\text { Inhibition }\end{array}$ & $\begin{array}{c}\text { Absorb- } \\
\text { ance }\end{array}$ & $\begin{array}{c}\% \\
\text { Inhibition }\end{array}$ \\
\hline $\mathrm{A}$ & 0.0189 & 82.81 & 0.0214 & 80.54 & 0.041 & 62.72 & 0.031 & 71.81 \\
\hline B & 0.0165 & 85.00 & 0.0860 & 21.81 & 0.067 & 39.09 & 0.078 & 29.09 \\
\hline $\mathrm{C}$ & 0.0084 & 92.36 & 0.0359 & 67.36 & 0.029 & 73.63 & 0.038 & 65.45 \\
\hline $\mathrm{D}$ & 0.0693 & 37.00 & 0.0220 & 80.00 & 0.005 & 95.45 & 0.010 & 90.90 \\
\hline Ascorbic acid & 0.0175 & 84.09 & 0.0268 & 75.63 & 0.0231 & 79.00 & 0.0566 & 48.54 \\
\hline
\end{tabular}

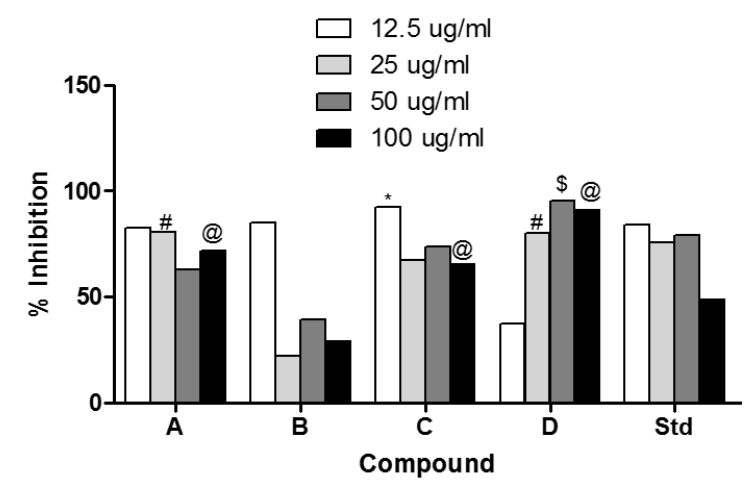

Fig. 1: Graph shows \% inhibition of free radicals

Where, * $12.5 \mathrm{ug} / \mathrm{ml}$ vs Ascorbic acid $12.5 \mathrm{ug} / \mathrm{ml}$

\# $25 \mathrm{ug} / \mathrm{ml}$ vs Ascorbic acid $25 \mathrm{ug} / \mathrm{ml}$

$\$ 50 \mathrm{ug} / \mathrm{ml}$ vs Ascorbic acid 50ug/ml

@ $100 \mathrm{ug} / \mathrm{ml}$ vs Ascorbic acid $100 \mathrm{ug} / \mathrm{ml}$ 
Table 5a: Zone of Inhibition Gram Positive Bacteria

\begin{tabular}{|c|c|c|c|c|c|c|c|c|}
\hline \multirow{3}{*}{ Compound } & \multicolumn{8}{|c|}{ Zone of inhibition(mm) } \\
\hline & \multicolumn{4}{|c|}{ B.subtilis } & \multicolumn{4}{|c|}{ S.aureus } \\
\hline & $25 \mu \mathrm{g}$ & $50 \mu \mathrm{g}$ & $75 \mu g$ & $100 \mu \mathrm{g}$ & $25 \mu \mathrm{g}$ & $50 \mu \mathrm{g}$ & $75 \mu \mathrm{g}$ & $100 \mu \mathrm{g}$ \\
\hline $\mathrm{A}$ & 9.2 & 8.2 & 10.0 & 9.2 & - & - & - & 13.2 \\
\hline B & 8.0 & 8.2 & 8.7 & 9.5 & - & - & - & - \\
\hline $\mathrm{C}$ & 11.7 & 9.2 & 9.5 & 9.75 & - & 10.2 & - & - \\
\hline $\mathrm{D}$ & 9.0 & 9.5 & 1.07 & 1.02 & - & - & - & - \\
\hline Amoxicillin & 11.0 & 12.7 & 14.2 & 16.0 & 10.1 & 11.5 & 11.9 & 12.8 \\
\hline
\end{tabular}

(-) indicate no zone of inhibition

Table5b: Observations of Zone of inhibition (Gram -ve)

\begin{tabular}{|c|c|c|c|c|c|c|c|c|}
\hline \multirow{3}{*}{ Compound } & \multicolumn{8}{|c|}{ Zone of inhibition(mm) } \\
\hline & \multicolumn{4}{|c|}{ E.coli } & \multicolumn{4}{|c|}{ P.aeroginosa } \\
\hline & $25 \mu \mathrm{g}$ & $50 \mu g$ & $75 \mu \mathrm{g}$ & $100 \mu \mathrm{g}$ & $25 \mu \mathrm{g}$ & $50 \mu \mathrm{g}$ & $75 \mu \mathrm{g}$ & $100 \mu \mathrm{g}$ \\
\hline $\mathbf{A}$ & 10.2 & 11.7 & 12.7 & 10.5 & 11.0 & 13.0 & 14.7 & 15.5 \\
\hline B & - & - & 12.0 & 10.5 & 11.2 & 10.7 & 11.0 & 13.5 \\
\hline $\mathbf{C}$ & - & - & 12.5 & 8.2 & 11.2 & 11.0 & 11.7 & 14.5 \\
\hline D & - & 11.2 & 10.5 & - & 11.7 & 13.7 & 12.0 & 13.2 \\
\hline Amoxicillin & 11.5 & 11.9 & 12.8 & 14.2 & 14.5 & 15.5 & 15.2 & 20.2 \\
\hline
\end{tabular}

(-) indicate no zone of inhibition

\section{Conclusion}

The four synthesized chalcones were screened for their antioxidant and antimicrobial activity. The antioxidant study results show that all the compounds show moderate to high antioxidant activity as compare to the reference compound that is ascorbic acid. It was found that the chalcones posseses more antioxidant activity as compare to ascorbic acid.

The antimicrobial study shows that all the four chalcones possess less antimicrobial activity as compare to standard towards the gram positive bacteria (B.subtilis). The synthesized chalcones have more activity against the gram negative bacteria.

\section{Acknowledgement}

The authors are thankful to the Principal, SKB college of Pharmacy for providing the necessary facilities for carrying out the work.

\section{References}

1. Ganorkar SL, Vignesh UN. "Synthesis and pharmacological properties of chalcones: a review". Research on Chemical Intermediates 2017;43:6043-77.

2. Patil CB, Mahajan SK, Katti SA. "Chalcone: A versatile Molecule”. J Pharm Sci Res 2009;1:11-22.

3. Prasad YR, Kumar PR, Deepti CA, Ramana MV. "Synthesis and antimicrobial activity of some novel chalcones of 2-hydroxy-1-acetophenone and 3-acetyl coumarin" Eur J Chem 2006;3:236-41.

4. Liu UM, Wilairat P, Croft SL, Tan AL, Go M. "Structure-activity relationships of antileishmanail and antimalarial chalcones" Bioorg Med Chem 2003;11:27-9

5. Tatsuzaki J, bestow KF, Nakagawa-Goto k, Nakamura S, Itokawa $\mathrm{H}$, Lee KH. "Dehydrozingerone, Chalcone and Isoeugenol analogues as in vitro anti acancer agents". $J$ Nat Prod 2006;69:1445-9.

6. Narender T, Reddy KP. "A simple and highly efficient method for the synthesis of chalcone usinf borontriflouroetherate". Tetrahydron Lette 2007;48:317780 .
7. Gupta J K. Gupta K R, Singh SV. "Chalcones: A Review On Synthesis, Chemical Properties And Biological Activities", Res Pharm 2017;1:1-10.

8. Alam MN, Bristi NJ, Raffiquzzamann. "Review on invivo and in-vitro method of evaluation of antioxidant activity". Saudi Pharm J 2013;21:143-52.

9. Saleh M, Abbott S, Perron V, Lauzon C, Penney C, Zacharie B." Synthesis and antimicrobial activity of 2fluorophenyl-4, 6-disubstituted[1,3,5]triazines. Bioorg. Med Chem Lette 2010;20:945-9. 